\title{
In vitro effects of emodin on peritoneal macrophages that express membrane-bound CD14 protein in a rat model of severe acute pancreatitis/systemic inflammatory response syndrome
}

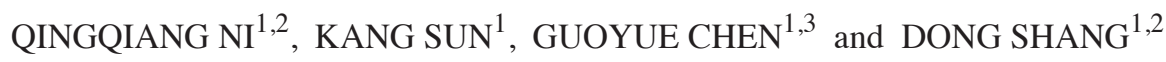 \\ ${ }^{1}$ Department of General Surgery, First Affiliated Hospital, Dalian Medical University, Dalian, Liaoning 116011; \\ ${ }^{2}$ College (Institute) of Intergrative Medicine, Dalian Medical University, Dalian, Liaoning 116044; \\ ${ }^{3}$ Department of Radiology, Jinan Municipal Central Hospital, Jinan, Shandong, 250013, P.R. China
}

Received August 6, 2013; Accepted October 28, 2013

DOI: $10.3892 / \mathrm{mmr} .2013 .1771$

\begin{abstract}
Emodin is the main active constituent of rhubarb and is often used in Chinese herbal medicine for the treatment of systemic inflammatory response syndrome (SIRS). The present study aimed to determine the in vitro effects of emodin on the expression of membrane-bound cluster of differentiation 14 (mCD14) protein in peritoneal macrophages (pMФs). The severe acute pancreatitis (SAP)/SIRS model was established in Sprague-Dawley (SD) rats via retrograde injection of $1.5 \%$ sodium deoxycholate into the common biliopancreatic duct. The 40 SD rats were randomly divided into the sham-operated $(\mathrm{n}=10)$ group $(\mathrm{SO})$ and the model group $(\mathrm{n}=30)$. After $24 \mathrm{~h}$, pMФs were harvested and the model group was randomly divided into three subgroups ( $\mathrm{n}=10$ per group), the $5 \mu \mathrm{g} / \mathrm{ml}$ emodin group (EMO), the $0.1 \mu \mathrm{mol} / \mathrm{ml}$ dexamethasone group (DEX) and the SIRS/ SAP group (SI). Treatment agents were administered following macrophage adhesion for $24 \mathrm{~h}$. Compared with that of the SO group, the SI group showed significantly increased pathological changes $(\mathrm{P}<0.01)$. Compared with that of the SO group, mCD14 expression in $\mathrm{pM} \Phi$ s was significantly
\end{abstract}

Correspondence to: Dr Dong Shang, Department of General Surgery, First Affiliated Hospital, Dalian Medical University, 222 Zhongshan Road, Dalian, Liaoning 116011, P.R. China

E-mail: tougao1971@163.com

Abbreviations: mCD14, membrane-bound CD14 receptor; sCD14, soluble CD14 receptor; SO, sham-operated group; EMO, emodin group; DEX, dexamethasone group; SI, SIRS/SAP group; SAP, severe acute pancreatitis; SIRS, systemic inflammatory response syndrome; MODS, multiple organ dysfunction syndrome; MФs, macrophages; pMФs, peritoneal macrophages; PMN, polymorphonuclear neutrophil; LPS, lipopolysaccharide; LPB, lipopolysaccharide binding protein

Key words: emodin, severe acute pancreatitis, systemic inflammatory response syndrome, macrophage, membrane-bound cluster of differentiation 14 protein. decreased in the SI group $(\mathrm{P}<0.01)$. Additionally, compared with that of the SI group, mCD14 expression in pMФs was significantly increased in the EMO group $(\mathrm{P}<0.01)$ and in the DEX group $(\mathrm{P}<0.01)$. Compared with that of the DEX group, $\mathrm{mCD} 14$ expression in $\mathrm{pM} \Phi$ s was significantly increased in the EMO group $(25.60 \pm 2.79$ vs. $20.87 \pm 1.99 ; \mathrm{P}<0.01)$. The pathological changes observed in the pancreas of rats in the model groups were more severe than that of the SO group. Moreover, mCD14 expression levels in $\mathrm{pM} \Phi$ s were significantly decreased in the SI group. The pathological changes of each intervention group improved to various degrees, particularly in the EMO group.

\section{Introduction}

Acute pancreatitis is currently one of the most intractable diseases in the surgical acute abdomen. Due to the high incidence rate and rapid progression, particularly for severe acute pancreatitis (SAP) with systemic inflammatory response syndrome (SIRS), the mortality rate of acute pancreatitis is high $(1,2)$. SIRS is an early manifestation of multiple organ dysfunction syndrome (MODS) and multiple organ failure (MOF) $(1,2)$.

It has been previously demonstrated that the polymorphonuclear neutrophil (PMN) life cycle is prolonged and apoptosis is delayed during infection, trauma and other stresses, which subsequently promotes inflammatory reactions that result in organ injury (3-8). Inflammatory reactions are worsened unless apoptotic PMNs are ameliorated. Therefore, delayed apoptosis of PMNs and the insufficient phagocytosis of apoptotic cells can increase inflammation. The majority of apoptotic cells in vivo are removed by macrophages (MФs). МФs identify, adhere and phagocytoze apoptotic PMNs to subsequently inhibit inflammatory reactions and promote inflammation resolution (9). Membrane-bound CD14 (mCD14) is one of the main receptors for $\mathrm{M} \Phi$ recognition, inducing the phagocytosis of apoptotic neutrophils (10). In the present study, a model of SAP/SIRS was established in rats to investigate the in vitro effects of emodin compared with that of dexamethasone (DEX) on the expression levels of $\mathrm{mCD} 14$ protein in peritoneal MФs (pMФs). 


\section{Materials and methods}

Animals. Healthy male Sprague-Dawley (SD) rats (weight, 220-250 g) were provided by the Laboratory Animal Center of Dalian Medical University (Dalian, China). Forty SD rats were randomly divided into the sham-operated group $(\mathrm{SO})(\mathrm{n}=10)$ and the model group $(\mathrm{n}=30)$. After $24 \mathrm{~h}, \mathrm{pM} \Phi$ s were harvested and the model group was randomly divided into three groups ( $\mathrm{n}=10 \mathrm{in}$ each group); the $5 \mu \mathrm{g} / \mathrm{ml}$ emodin group (EMO), the $0.1 \mu \mathrm{mol} / \mathrm{ml} \mathrm{DEX}$ and the SIR/SAP group (SI). The therapeutic agents were administered following $\mathrm{pM} \Phi$ adhesion for $24 \mathrm{~h}$. The study was approved by the Ethics Committee of the First Affiliated Hospital of Dalian Medical University (Dalian, Liaoning, China).

Equipment. High-speed refrigerated 5840R centrifuge (Eppendorf, Hamburg, Germany), flow cytometry (BD Biosciences, Franklin Lakes, NJ, USA) and an immunofluorescence microscope (CX31-32RFL; Olympus, Tokyo, Japan) were used in this study.

Reagents and drugs. RPMI-1640 medium, fetal bovine serum, fluorescein isothiocyanate (FITC)-conjugated goat anti-rabbit, rabbit anti-CD14 polyclonal antibody and emodin were purchased from Sigma (St. Louis, MO, USA). Dextran T500 was purchased from Sigma.

SAP/SIRS model establishment. The SAP/SIRS rat model was established as described previously (11). Briefly, rats fasted for $12 \mathrm{~h}$ prior to surgery, but had access to water ad libitum. Rats were then anesthetized intraperitoneally with an injection of $10 \%$ chloral hydrate (Sigma) at a dose of $0.3 \mathrm{ml} / 100 \mathrm{~g}$. To expose the duodenum, a midline laparotomy was performed. A $1 \mathrm{ml}$ syringe needle was inserted through the contralateral intestinal wall of the duodenal papilla into the bile and pancreatic ducts, and clamped using a noninvasive bulldog clamp, followed by slow retrograde perfusion of $1.5 \%$ sodium deoxycholate $(0.1 \mathrm{ml} / 100 \mathrm{mg})$ for $60 \mathrm{sec}$. The duodenal papilla was pinched to prevent back flow. The SO group were only subjected to a celiotomy.

Isolation, purification, culture and administration of pMФs. Trypan blue staining was performed to detect the $\mathrm{pM} \Phi$ survival rates and cell purity was $>98$ and $>95 \%$ in the SO and model groups, respectively. The majority of cells showed the morphological features of МФs. pМФs from each group were seeded in 6 -well culture plates and treated with $5 \mu \mathrm{g} / \mathrm{ml}$ emodin or $0.1 \mu \mathrm{mol} / \mathrm{ml}$ DEX. The SI and SO groups were untreated. Cells were then incubated at $37^{\circ} \mathrm{C}$ with $5 \% \mathrm{CO}_{2}$ for $24 \mathrm{~h}$.

Pathomorphological observation of pancreatic tissue. Pancreatic tissue sections, cut from the formalin-fixed, paraffin-embedded tissues, were routinely assessed with hematoxylin and eosin staining. The pathological scoring was performed according to the method of Kaiser et al (11).

Detection of $m C D 14$ protein expression in $p M \Phi$ s using immunofluorescence. Glass slides were placed into 24-well culture plates. РМФ concentration was adjusted to $5 \times 10^{6}$ cells $/ \mathrm{ml}$. After $30 \mathrm{~min}$, cells in $2 \mathrm{ml}$ RPMI-1640 containing serum were added to the culture plates and incubated at $37^{\circ} \mathrm{C}$ with $5 \% \mathrm{CO}_{2}$ for $24 \mathrm{~h}$. Emodin $(5 \mu \mathrm{g} / \mathrm{ml})$ and DEX $(0.1 \mu \mathrm{mol} / \mathrm{ml})$ were respectively added into separate wells, followed by incubation at $37^{\circ} \mathrm{C}$ with $5 \% \mathrm{CO}_{2}$ overnight. Cells were harvested, washed with phosphate-buffered saline (PBS) three times, dried, fixed with $4 \%$ paraformaldehyde for $30 \mathrm{~min}$ and then washed again with PBS three times. One drop of non-immune animal serum was added to each slide and incubated at room temperature for $30 \mathrm{~min}$. Additionally, $100 \mu \mathrm{l}$ rabbit anti-CD14 polyclonal antibody (1:100; Sigma) was added to each slide and incubated at room temperature for $30 \mathrm{~min}$ in the dark. Slides were washed with PBS three times for $5 \mathrm{~min}$ and then dried. Fluorescein isothiocyanate (FITC)-conjugated goat anti-rabbit antibody (50 $\mu 1$; Sigma) was added to each slide and incubated at room temperature for $30 \mathrm{~min}$. Slides were washed with PBS three times for $5 \mathrm{~min}$, dried and observed under a fluorescence microscope (Olympus). Positive reactions were detected under a fluorescence microscope as green fluorescent particles, indicating the presence of $\mathrm{pM} \Phi \mathrm{mCD} 14$ receptors.

Detection of $m C D 14$ expression in $p M \Phi$ s using flow cytometry. After $24 \mathrm{~h}$ of culture, cells were washed three times in pre-warmed Hank's solution (Beyotime, Shanghai, China) and then trypsinized with $0.25 \%$ trypsin at $37^{\circ} \mathrm{C}$ for 5-6 min. When $90 \%$ of the adhered pMФs appeared round and transparent as observed under an inverted microscope (Nikon Eclipse TS100; Nikon Corporation, Tokyo, Japan), digestion was terminated with 10-20 ml RPMI-1640 medium and cells were triturated. Cells were centrifuged at $111.8 \mathrm{x} \mathrm{g}$ for $10 \mathrm{~min}$ at $4^{\circ} \mathrm{C}$. The supernatant was discarded and cells were incubated with $2 \mu \mathrm{l}$ rabbit anti-CD14 polyclonal antibody (Sigma) at room temperature for $1 \mathrm{~h}$, washed with PBS three times, centrifuged at $1,000 \mathrm{r} / \mathrm{min}(\mathrm{R}=10 \mathrm{~cm})$ for $10 \mathrm{~min}$ at $4^{\circ} \mathrm{C}$, and incubated with $2 \mu 1$ FITC-conjugated goat anti-rabbit antibody (Sigma) at room temperature for $15 \mathrm{~min}$. Cells were then washed three times with PBS and centrifuged at 1,000 r/min for $10 \mathrm{~min}$ at $4^{\circ} \mathrm{C}$. Cells were resuspended in $1 \mathrm{ml} \mathrm{PBS}$ and $\mathrm{mCD} 14$ expression was determined by flow cytometry.

Statistical analysis. Data were analyzed using SPSS software, version 11.5 (SPSS, Inc., Chicago, IL, USA) and expressed as the mean \pm standard deviation. Enumeration data were analyzed using the exact probability of a 4 -fold table and measurement data with completely random analysis of variance. Paired comparison was performed using a q-test. $\mathrm{P}<0.05$ was considered to indicate a statistically significant difference at an $\alpha$ level of 0.05 .

\section{Results}

Clinical manifestations. Following injection of $1.5 \%$ sodium deoxycholate, rats exhibited rapid breathing and symptoms were aggravated with prolonged time. Rats also presented with cyanosis of the mucosa of the skin, unconsciousness and occasionally death (mortality rate was $20 \%$ in the model groups).

Gross observation. Immediately following injection of $1.5 \%$ sodium deoxycholate, the pancreatic gland presented with evident regional or diffuse hyperemia and edema, with increased pancreatic envelope tension. After 24 h, pancreatic 
Table I. Comparison of the pathological changes in the SO and SI groups.

\begin{tabular}{lccccc}
\hline Group & No. of rats & Edema & Inflammation & Hemorrhage & Necrosis \\
\hline SO & 10 & $0.40 \pm 0.07$ & 0 & 0 & 0 \\
SI & 8 & $3.50 \pm 0.21$ & $2.70 \pm 0.16$ & $2.30 \pm 0.19$ & $2.80 \pm 0.25$ \\
\hline
\end{tabular}

SO, sham-operated group; SIRS/SAP, SI group. Values are expressed as the mean \pm standard deviation.

hemorrhaging, necrosis and bloody ascites were observed in the surviving rats of the model groups. In addition to yellow saponaceous spots in the greater omentum and common bile duct, lung hyperemia, edema, bleeding in the lung, stomach edema, paralytic expansion, liver swelling and kidney augmentation were observed. However, in the SO group, mild edema of gastrointestinal mucosa and exudation in the abdominal cavity were observed.

Pathological changes in pancreatic tissues observed by light microscopy. The SO group exhibited clear pancreatic lobule structures. The model groups presented with necrosis in the pancreatic glandular parenchyma, bleeding, fatty degeneration, erythrocyte stasis, angiectasis and PMN infiltration into the tissue space and parenchyma. Compared with the SO group, the SI group showed significantly increased pathological changes (edema, $3.50 \pm 0.21$ vs. $0.40 \pm 0.07$; inflammation, $2.70 \pm 0.16$ vs. 0 ; bleeding, $2.30 \pm 0.19$ vs. 0 and necrosis, $2.80 \pm 0.25$ vs. 0 ; $\mathrm{P}<0.01$; Table I and Fig. 1).

mCD14 expression in $p M \Phi s$ in each group. As detected by immunofluorescence, green fluorescent particles were observed in the SO, EMO, DEX and SI groups, indicating the presence of $\mathrm{pM} \Phi \mathrm{mCD} 14$ receptors (Fig. 2).

The mCD14 expression levels in pMФs in each group detected by flow cytometry (mean \pm standard deviation) are shown in Table II and Fig. 3. Compared with the SO group, the expression levels of mCD14 in pMФs were significantly decreased in the SI group (28.55 \pm 2.53 vs. $14.76 \pm 2.84 ; \mathrm{P}<0.01)$. Compared with the SI group, the expression levels of mCD14 in $\mathrm{pM} \Phi$ s were significantly increased in the EMO $(25.60 \pm 2.79$ vs. $14.76 \pm 2.84 ; \mathrm{P}<0.01)$ and $\mathrm{DEX}(20.87 \pm 1.99$ vs. $14.76 \pm 2.84$; $\mathrm{P}<0.01)$ groups. Compared with the DEX group, mCD14 expression levels in $\mathrm{pM} \Phi$ s were significantly increased in the EMO group $(25.60 \pm 2.79$ vs. $20.87 \pm 1.99$; $\mathrm{P}<0.01)$.

\section{Discussion}

There are numerous receptors, which are involved in the recognition and phagocytosis of apoptotic cells, on the surface of phagocytes. The protein, CD14, is one of the five macrophage receptors located on the surface of phagocytes, which is involved in the recognition and phagocytosis of apoptotic cells. The expression of CD14 is tissue and cell specific. CD14 is mainly expressed on the surface of mononuclear MФs and is weakly expressed on the surface of neutrophils and lymphocytes (12-15). The expression levels of CD14 are different from that of various types of mononuclear MФs; the expression of CD14 is stronger on the surface of $\mathrm{pM} \Phi$ s and weaker on
Table II. mCD14 expression levels in pMФs in each group as detected by flow cytometry.

\begin{tabular}{lcc}
\hline Groups & No. of rats & Expression rate $(\%)$ \\
\hline SO & 10 & $28.55 \pm 2.53$ \\
SI & 8 & $14.76 \pm 2.84^{\mathrm{a}}$ \\
EMO & 8 & $25.60 \pm 2.79^{\mathrm{b}}$ \\
DEX & 8 & $20.87 \pm 1.99^{\mathrm{b}, \mathrm{c}}$ \\
\hline
\end{tabular}

${ }^{\mathrm{a}} \mathrm{P}<0.01$, vs. the SO group; ${ }^{\mathrm{b}} \mathrm{P}<0.01$, vs. the SI group; and ${ }^{\mathrm{c}} \mathrm{P}<0.01$, vs. the EMO group. SO, sham-operated group; SI, SIRS/SAP group; EMO, emodin group; DEX, dexamethasone group; $\mathrm{pM} \Phi$, peritoneal macrophage; mCD14, membrane-bound cluster of differentiation 14 receptor. Values are expressed as the mean \pm standard deviation.

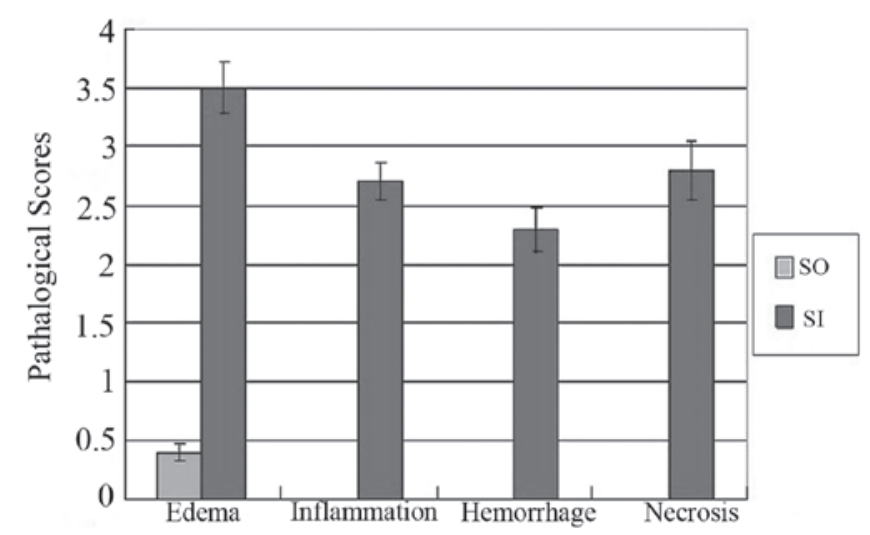

Figure 1. Comparison of the pathological changes in the SO and SI groups. Compared with the SO group, the pathological changes of the SI group were more severe according to the pathological scoring. SO, sham-operated group; SI, SIRS/SAP group.

the surface of alveolar macrophages, Kupffer and microglia cells (16). Moreover, numerous factors can affect the expression levels of CD14 in the development process of monocytes to MФs. There are two forms of CD14, termed mCD14 and soluble CD14 receptor (sCD14). sCD14 appears in the serum due to proteolytic cleavage and phospholipase D-induced mCD14 shedding from monocytes (10). mCD14 is one of the predominant receptors that $М \Phi$ s recognize inducing the phagocytosis of apoptotic cells. CD14 is a receptor for the serum lipopolysaccharide (LPS) complex or LPS binding protein (LBP) and may be shed from the monocyte surface to inhibit the release of tumor necrosis factor- $\alpha$ (TNF- $\alpha)$ (17). In addition, Marchant et al (18) found that a low concentration 

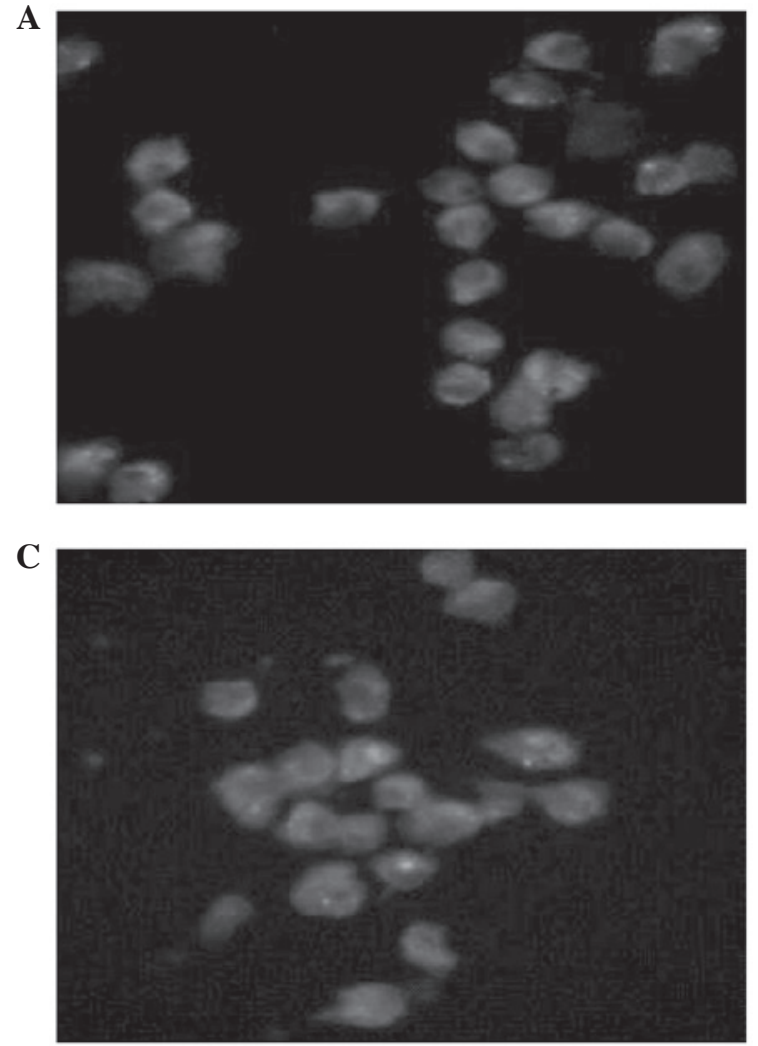
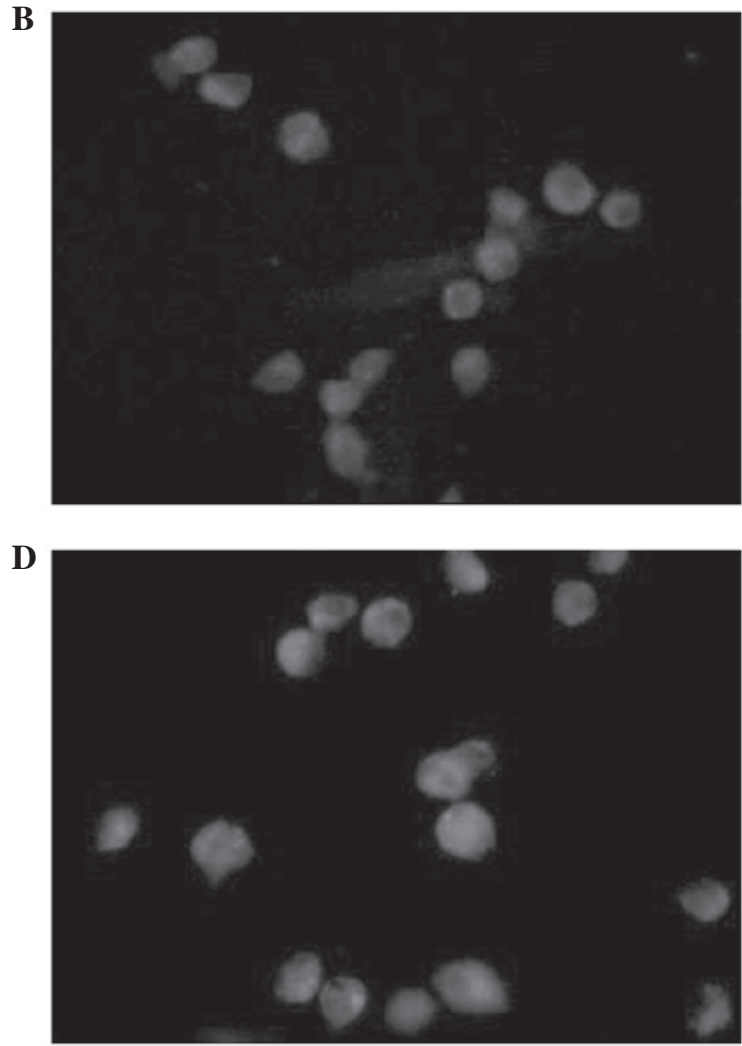

Figure 2. As detected by immunofluorescence, green fluorescent particles were found in the (A) SO, (B) SI, (C) EMO and (D) DEX groups, indicating the presence of $\mathrm{pM} \Phi \mathrm{mCD} 14$ receptors in each group (magnification, x100). SO, sham-operated group; SI, SIRS/SAP group; EMO, emodin group; DEX, dexamethasone group; $\mathrm{pM} \Phi$, peritoneal macrophage; $\mathrm{mCD} 14$, membrane-bound cluster of differentiation 14 receptor.

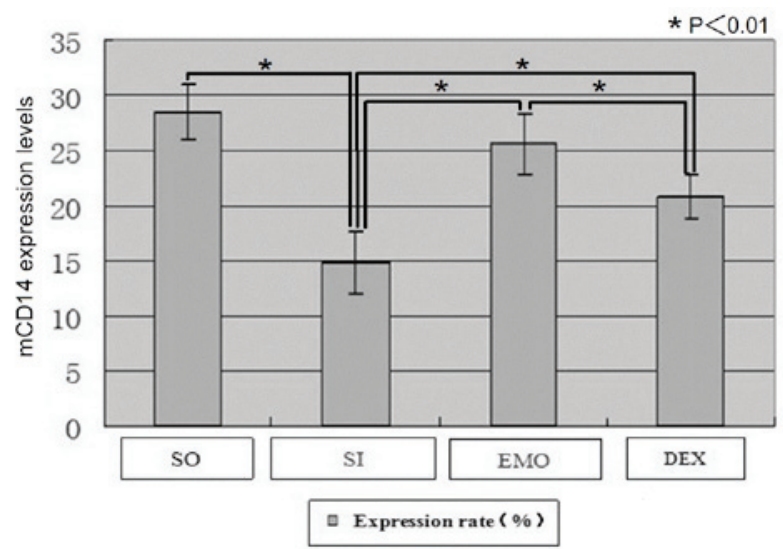

Figure 3. mCD14 expression levels in pMథs in each group detected by flow cytometry. Compared with the SO group, mCD14 expression levels in $\mathrm{pM} \Phi \mathrm{s}$ were significantly decreased in the model groups. Compared with the SO group, mCD14 expression levels in $\mathrm{pM} \Phi \mathrm{s}$ were significantly decreased in the SI group $(\mathrm{P}<0.01)$. Compared with the SI group, $\mathrm{mCD} 14$ expression levels were significantly increased in the EMO $(\mathrm{P}<0.01)$ and $\mathrm{DEX}(\mathrm{P}<0.01)$ groups Compared with the DEX group, $\mathrm{mCD} 14$ expression levels in $\mathrm{pM \Phi s}$ were significantly increased in the EMO group $(\mathrm{P}<0.01)$. РMФ, peritoneal macrophage; $\mathrm{mCD} 14$, membrane-bound cluster of differentiation 14 receptor; SO, sham-operated group; SI, SIRS/SAP group; EMO, emodin group; DEX, dexamethasone group.

of LPS increased the expression levels of monocyte mCD14. In the present study, mCD14 protein expression levels in pMФs were significantly decreased following the induction of SAP/SIRS compared with that of the SO group. Therefore, it was speculated that SIRS induced intestinal mucosal barrier damage and bacterial translocation causes intestinal endotoxemia. After binding to LBP receptors on MФs thereby forming LPS-LBP complexes, endotoxins could induce MФs to synthesize and release a large quantity of TNF- $\alpha$ and other inflammatory mediators that trigger inflammatory reactions (16,19-22). Additionally, mCD14 may be shed from the monocyte surface accompanied by a decrease in the levels of mCD14.

Dahuang (Rhubarb), a Chinese herb, has been found to be clinically effective for the treatment of acute pancreatitis (23-26). Emodin is the main active component of Dahuang. Previous studies have shown that emodin affects bacteriostasis, catharsis, releases Oddi sphincter spasms, inhibits abnormal metabolism of vasoactive substances (eicosenoic acid), improves microcirculation and antagonizes coagulation and thrombus formation $(23,27,28)$. The present study showed that emodin significantly increased mCD14 protein expression levels in pMФs in rats with SAP/SIRS compared with that of the SI $(\mathrm{P}<0.01)$, which subsequently enhanced the identification and phagocytosis capacity of pMФs and relieved inflammatory reactions.

In 1952, Stephensen et al (29) first reported the application of glucocorticoids to treat acute pancreatitis. However, the mechanisms underlying their effect have not been fully elucidated. The effects of glucocorticoids on inflammation via receptor mediation may trigger anti-inflammation. Glucocorticoids inhibit inflammatory exudation, leukocytic infiltration, inflammatory mediator production and release, as 
well as improve microcirculation, alleviate endotoxemia and induce apoptosis of pancreatic acinar cells, thereby reducing the degree of pancreatic necrosis in SAP $(30,31)$. A previous study demonstrated that pancreatic cell apoptosis occurs during acute pancreatitis (32). Animal studies have also indicated that DEX induces pancreatic cell apoptosis, stabilizes the internal environment and attenuates inflammation in pancreatic tissues $(31,33)$. In the present study, it was demonstrated that DEX increased mCD14 expression levels in pMФs.

In this study, it was demonstrated that compared with the SO group, mCD14 expression levels in pMФs were significantly decreased in the model groups. In vitro emodin or DEX administration increased the expression levels of mCD14 in pMФs. Notably, emodin exhibited more significant effects than DEX, suggesting that emodin and DEX may be used together due to their respective advantages.

\section{Acknowledgements}

This study was supported by the National Natural Science Foundation of China (grant no. 81072918/H2902).

\section{References}

1. Frossard JL, Steer ML and Pastor CM: Acute pancreatitis. Lancet 371: 143-152, 2008.

2. Doctor N, Agarwal P and Gandhi V: Management of severe acute pancreatitis. Indian J Surg 74: 40-46, 2012.

3. Blomgran R, Patcha Brodin V, Verma D, et al: Common genetic variations in the NALP3 inflammasome are associated with delayed apoptosis of human neutrophils. PLoS One 7: e31326, 2012.

4. Paunel-Görgülü A, Kirichevska T, Lögters T, Windolf J and Flohé S: Molecular mechanisms underlying delayed apoptosis in neutrophils from multiple trauma patients with and without sepsis. Mol Med 18: 325-335, 2012.

5. Schwartz JT, Bandyopadhyay S, Kobayashi SD, et al: Francisella tularensis alters human neutrophil gene expression: insights into the molecular basis of delayed neutrophil apoptosis. J Innate Immun 5: 124-136, 2013.

6. Terashima M, Aoyama-Ishikawa M, Ueda T, et al: The effects of $n-3$ polyunsaturated fatty acid-rich total parenteral nutrition on neutrophil apoptosis in a rat endotoxemia. J Clin Biochem Nutr 52: 154-159, 2013.

7. Shang D, Wang BZ, Bi W, Chen HL, Qi QH and Guan FL: Abnormal polymorphonuclear neutrophils apoptosis in systemic inflammatory response syndrome. Dalian Yike Daxue Xuebao 28: 161-163, 2006.

8. Zhang J, He J, Xia J, Chen Z and Chen X: Delayed apoptosis by neutrophils from COPD patients is associated with altered Bak, Bcl-xl, and Mcl-1 mRNA expression. Diagn Pathol 7: 65, 2012.

9. Willems CH, Urlichs F, Seidenspinner S, Kunzmann S, Speer CP and Kramer BW: Poractant alfa (Curosurf $\left.{ }^{\circledR}\right)$ increases phagocytosis of apoptotic neutrophils by alveolar macrophages in vivo. Respir Res 13: 17, 2012.

10. Schütt C: CD14. Int J Biochem Cell Biol 31: 545-549, 1999.

11. Kaiser AM, Saluja AK, Sengupta A, Saluja M and Steer ML: Relationship between severity, necrosis, and apoptosis in five models of experimental acute pancreatitis. Am J Physiol 269: C1295-C1304, 1995.

12. Pietruska M, Zak J, Pietruski J and Wysocka J: Evaluation of mCD14 expression on monocytes and the blood level of sCD14 in patients with generalized aggressive periodontitis. Adv Med Sci 51 (Suppl 1): S166-S169, 2006.

13. Wright SD, Ramos RA, Tobias PS, Ulevitch RJ and Mathison JC: CD14, a receptor for complexes of lipopolysaccharide (LPS) and LPS binding protein. Science 249: 1431-1433, 1990.
14. Klaassen EM, Thönissen BE, van Eys G, Dompeling E and Jöbsis Q: A systematic review of CD14 and toll-like receptors in relation to asthma in Caucasian children. Allergy Asthma Clin Immunol 9: 10, 2013.

15. Fadok VA, Warner ML, Bratton DL and Henson PM: CD36 is required for phagocytosis of apoptotic cells by human macrophages that use either a phosphatidylserine receptor or the vitronectin receptor (alpha v beta 3). J Immunol 161: 6250-6257, 1998.

16. Ziegler-Heitbrock HW and Ulevitch RJ: CD14: cell surface receptor and differentiation marker. Immunol Today 14: 121-125, 1993.

17. Bazil V and Strominger JL: Shedding as a mechanism of down-modulation of CD14 on stimulated human monocytes. J Immunol 147: 1567-1574, 1991.

18. Marchant A, Duchow J, Delville JP and Goldman M: Lipopolysaccharide induces up-regulation of CD14 molecule on monocytes in human whole blood. Eur J Immunol 22: 1663-1665, 1992.

19. Nathens AB, Bitar R, Marshall JC, et al: Antioxidants increase lipopolysaccharide-stimulated TNF alpha release in murine macrophages: role for altered TNF alpha mRNA stability. Shock 16: 361-367, 2001.

20. Hsiao HB, Wu JB, Lin H and Lin WC: Kinsenoside isolated from Anoectochilus formosanus suppresses LPS-stimulated inflammatory reactions in macrophages and endotoxin shock in mice. Shock 35: 184-190, 2011.

21. Li S, Ni Z, Cong B, et al: CCK-8 inhibits LPS-induced IL-1beta production in pulmonary interstitial macrophages by modulating PKA, p38, and NF-kappaB pathway. Shock 27: 678-686, 2007.

22. Boonstra A, Rajsbaum R, Holman M, et al: Macrophages and myeloid dendritic cells, but not plasmacytoid dendritic cells, produce IL-10 in response to MyD88- and TRIF-dependent TLR signals, and TLR-independent signals. J Immunol 177: 7551-7558, 2006.

23. Li Z, Xia X, Zhang S, Zhang A, Bo W and Zhou R: Up-regulation of Toll-like receptor 4 was suppressed by emodin and baicalin in the setting of acute pancreatitis. Biomed Pharmacother 63: 120-128, 2009.

24. Wang G, Sun B, Gao Y, Meng QH and Jiang HC: The effect of emodin-assisted early enteral nutrition on severe acute pancreatitis and secondary hepatic injury. Mediators Inflamm 2007: 29638, 2007.

25. Yang CY, Shen L, Xie ZG, Jiang X, Liang N and Chen ZH: Experimental studies of therapeutic effect of Rheum officinale on acute pancreatitis. Zhong Yao Cai 34: 84-88, 2011 (In Chinese).

26. Zheng SH, Tong QY, Zhu ZY,Li ZY and You H: Effect of Rhubarb administered via different routes on blood inflammatory cytokines levels of patients with severe acute pancreatitis. Zhongguo Wei Zhong Bing Ji Jiu Yi Xue 23: 437-438, 2011 (In Chinese).

27. Kuo YC, Meng HC and Tsai WJ: Regulation of cell proliferation, inflammatory cytokine production and calcium mobilization in primary human T lymphocytes by emodin from Polygonum hypoleucum Ohwi. Inflamm Res 50: 73-82, 2001.

28. Li A, Dong L, Duan ML, Sun K, Liu YY, Wang MX, et al: Emodin improves lipopolysaccharide-induced microcirculatory disturbance in rat mesentery. Microcirculation 20: 617-628, 2013.

29. Stephenson HE Jr, Pfeffer RB and Saypol GM: Acute hemorrhagic pancreatitis; report of a case with cortisone treatment. AMA Arch Surg 65: 307-308, 1952.

30. Jingmin O, Xiping Z, Chun W, Ping Y and Qian Y: Study of dexamethasone, baicalin and octreotide on brain injury of rats with severe acute pancreatitis. Inflamm Res 61: 265-275, 2012.

31. Zhang XP, Chen L, Hu QF, et al: Effects of large dose of dexamethasone on inflammatory mediators and pancreatic cell apoptosis of rats with severe acute pancreatitis. World J Gastroenterol 13: 5506-5511, 2007.

32. Jha RK, Ma Q, Sha $H$ and Palikhe M: Acute pancreatitis: a literature review. Med Sci Monit 15: RA147-RA156, 2009.

33. Ou JM, Zhang XP, Wu CJ, Wu DJ and Yan P: Effects of dexamethasone and Salvia miltiorrhiza on multiple organs in rats with severe acute pancreatitis. J Zhejiang Univ Sci B 13: 919-931, 2012. 